\title{
CORRESPONDENCE
}

\section{Insult to Medvedev}

SIR,-Many of your readers will have learnt of the shabby treatment of $\mathrm{Dr}$ Zhores Medvedev, the distinguished Russian biologist, by the Soviet authorities. Dr Medvedev was invited by the International Organizing Committee to address the International Gerontological Congress in Kiev last week, but the local organizers of the Congress refused to allow him to participate in the meeting in a scientific capacity. It is now reported that some forcible means was then used to cut short a private visit that he made to Kiev in order to meet his many scientific colleagues from abroad.

This gross insult to the international community of science will surely not go unnoticed. But more effective than verbal protests would be a systematic scrutiny of the credentials of Russian visitors to international conferences and other scientific occasions. It is well known, for example, that the persons who eventually arrive at such meetings from the Soviet Union are not always those distinguished scholars who have been personally invited, or applicants whose scientific standing has been checked in advance by the convenors of the conference. The exclusion of the unknown and incompetent "substitutes" who sometimes turn up would do no harm to our own scientific activities nor to the legitimate interests of the Soviet scientific community. Out of extreme courtesy, this policy, whose propriety is beyond question, has seldom been followed. In view of this unprecedented discourtesy by the Soviet authorities, it should now be established as our regular custom.

Yours faithfully, JOHN ZIMAN

University of Bristol,

H. H. Wills Physics Laboratory,

Royal Fort,

Tyndall Avenue,

Bristol BS8 1TL

\section{Nuclear Uncertainty}

SIR,-Your leader (Nature, 237, 474 ; 1972) on the second report of the Select Committee on Science and Technology for 1971/72 understandably follows the precedent set by the Committee in distorting the CBI's views on Harwell by selective quotation, but perhaps you will allow me to set the matter straight.

The CBI has at no time advocated that Harwell's non-nuclear work should be closed down, although when the Select Committee asked what the effect on industry of such a hypothetical closure would be, the reply was as quoted. Obviously such a closure would cause disruption if implemented suddenly, but the demands for the nonnuclear services at present supplied by Harwell to industry could eventually be satisfied by other laboratories if adequate notice were given.

Returning to the real world, however, the CBI view of publicly owned laboratories (including Harwell) is that they should work primarily for the Government or its agencies, but that their special skills and facilities should be made available to other users at properly costed rates. The CBI thinks that such contract work should form only a small part of the work of any Government laboratory, but is content to let the market decide the exact size of the activity, provided that the charges are an accurate reflexion of the cost of providing the service.

The only aspect of Harwell's work which the CBI suggested to the Select Committee was in need of special control was its speculative innovatory work described as "development of commercial agreements". The Select Committee appears to have taken this point, but in place of the CBI's proposed limitation of spending on such work to a fixed proportion of Harwell's expenditure, the Committee suggests supervision by an Industrial Advisory Committee which would presumably be held accountable in some way for the results of their advice.

It is not clear in what sense Harwell "pioneered industrial contract research" (IRD at Newcastle and others would no doubt have views on this matter), but the speed with which you pass from this statement to a discussion of Harwell's contract income tends to conceal the fact that about half this income comes not from industry but from Government departments. This source seems to the CBI to be entirely appropriate, and the proportion of income derived from it will no doubt increase in the post-Rothschild era, but this income is not industrial contract income. Whether Harwell will or will not achieve its projected income from industry of about $£ 3.5$ million by $1974 / 5$ remains to be seen, but the total $\mathrm{R}$ and $\mathrm{D}$ expenditure by industry which was put out to other sectors in 1968/69 (the latest year for which figures are available, see Economic Trends, No. 205, ix, November 1970) was only $£ 9$ million.

Yours faithfully, D. W. BUDWORTH

21 Tothill Street,

London SW1H $9 L P$

\section{Population Growth}

SIR,-A brief comment on your defence of the "backlash" against Dr Ehrlich and others (Nature, 237, $360 ; 1972$ ). The whole point about exponential growth and the factors which "cause growth rates (to) change in the course of time under the pressure of events" is contained in the last phrase of that quotation. It is all very well to observe populations failing to continue to expand indefinitely, but when one happens to be a member of the species concerned the "pressure of events" can, I am sure, be excessively unpleasant. It is precisely to avoid being subject to such environmental pressures (which in many ecological cases cause an eventual plunge, rather than merely a levelling-off, in population, and may be expected to do so especially in our case since we have the means artificially to stave off those pressures for a time) that conservationists are urging that voluntary steps be taken not to delay the onset of natural restraints a little (as the technologists can) but to contain man's population and activities within what his natural environment can indefinitely support. Certainly we need governmental and international machinery to ensure that these steps are taken, but, since much of the resistance to expansion comes from the vested interest of industrialists and economists, often intimately concerned in government, this is not so robust a goal as your unconvincingly optimistic article suggests.

$$
\begin{aligned}
& \text { Yours faithfully, } \\
& \text { ANTHONY WREN }
\end{aligned}
$$

26 Rosemont Court,

Rosemont Road,

Acton,

London W3 9LS 